\title{
Evaluación de las técnicas de doble difusión 5 e inmunoelectroforesis en hidatosis infantil en la casuística de un decenio
}

\author{
Clara Retamal G. '; Carlos Pérez B. '; Isabel Noemí H.'; \\ Ximena Aguilera M.'; Werner Apt B. ${ }^{+}$
}

\begin{abstract}
Ten years experience with serum double diffussion 5 and immune electrophoresis methods in the diagnosis of infantile echinococcosis
\end{abstract}

\begin{abstract}
From year 1982 throughout 1991 , double diffusion 5 and immLne electrophoresis were applied ia 500 serc from symplomalic children suspected of hydatid disease and from 70 conlrols affected by other confirmed parasitic diseases. One or more hydatid cysts were confirmed by surgery in 115 children. Double diffusion 5 and immune electrophoresis gave positive results in $7 B$ coses $\mid 67.8 \%$, and suspicious reactions in $16(13.9 \%)$. The highest sensitivity $[47,4 \%]$ was associaled is hepolic bocolicn of cysts. Arc 5 was icentified in $33.9 \%$ sera of confirmed coses and in $35 / 42$ broken cysis. In $35,11.5$ confirmed cases (30.4\%) iwo ba-ds were identitied ol double diffus an and immune electrophoresis, so the detection of arc 5 or wo $0^{\prime}$ ro"e pracipitalion bands in these resls was considered to be a positive criter'um. Tests positive sredictive value was $100 \%$ and their negative prediclive volue was $92.5 \%$, confirming that negarive serological resulis should nol exclude hyoatidosis
\end{abstract}

|Koy words: ecrinococcos's, hydaticasis. serodiagnosis.'

En Chile la hidatidosis es una zoonosis parasitaria importante, con prevalencia estimada de 7 por 100000 habitantes, e incidencia clínica superior a 800 casos por año ${ }^{1,2}$, de los cuales aproximadamente $20 \%$ se manifiestan en niños. Entre las técnicas aplicadas a su diagnóstico destacan la hemaglutinación indirecta (HAI), aglutinación de látex (AL), inmunofluorescencia indirecta (IFI) e inmunoprecipitación (IP), con variados rendimientos en adultos y niños ${ }^{3.4}$. Cada laboratorio, asistencial o de investigación, utiliza la que le resulte más fácil en su medio, siempre que sea sensible y especifico. Se sabe que ambas propiedades dependen de factores biológicos inherentes al huésped, al parásito (edad, localización, características del quiste, especie, etc.) y, además, de factores técnicos como calidad y origen de los antigenos utilizados, los que deben ser estandarizados en cada centro especializado $0^{4,5}$. Si bien en los últimos años

I. Departamento de Parasitologra, Unidades Sur y Oriente, Facultad de Medicina, Universidad de Chile. otras técnicas, como ELISA ${ }^{6.7}$ e inmunoelectro transferencia, complementan el diagnóstico, las de IP, doble difusión (DD5) e inmunoelectroforesis (IEF), siguen constituyendo un valioso aporte al laboratorio asistencial. En este trabajo retrospectivo se describe la experiencia de una década con el rendimiento de la DD5 y de la IEF en el diagnóstico de la hidatosis en pediatría.

\section{Material y Método}

Se efectuaron pruebas de DD5 e inmunoelectroforesis en 570 muestras de niños menores de 15 anos, provenientes de hospitales pediátricos de las areas Norte, Oriente y Sur de Santiago: 500 niños cuyo diagnóstico clínico probable era hidatosis y 70 con otras parasitosis confirmadas (ascariasis, tricocefalosis, fascioliasis, toxocariasis, amebiasis y giardiasis). De los 500 niños sintomáticos estudiados, en 115 se confirmó el diagnóstico en una intervención quirúrgica: 60 varones $(52,2 \%)$ y 55 niñas $(47,8 \%)$, de 5 a 14 años de edad, promedio 8 años 6 meses.

El antígeno soluble empleado en tas tócnicas fue preparado y estandarizado como ha sido previamente descrito ${ }^{3.4}$, a partic de líquido hidatídico de quistes hepáticos y puimonares de origen ovino de la XI región de Chile y del área 
metropolitana, centrifugado, dializado, liofilizado y, posteriormente, guardado en frascos estériles hasta su empleo, previa reconstitución en solución tampón. El contenido de nitrógeno total osciló entre 0,6 y $0,9 \mathrm{mg} / \mathrm{ml}$ y el antígeno obtenido presentó entre 9 y 11 arcos de precipitación en la inmunoelectroforeșis, incluyendo arco 5. Para la estandarización de esia técnica se emplearon dos grupos de sueros controles: sueros positivos con 7 o más bandas de precipitación además del arco 5 , provenientes de pacientes adultos con hidatidosis múltiple y sueros de pacientes (niños) que poseian no más de 2 bandas con arco 5 . Como control de la DD5 se emplearon sueros positivos confirmados con $\operatorname{arcos} 5$.

Las pruebas se practicaron en laminas portaobjeto corrientes, con agarosa $1 \%$ como soporte. El antígeno liofilizado se utilizó en concentración de $100 \mathrm{mg} / \mathrm{mol}$, diluido en tampon salino, fosfato (PBS), $\mathrm{pH} 7,4$ y posteriormente las muestras fueron teñidas con colorante rojo Ponceau o anido Schwarz para mejor visualización de las bandas. El criterio de positividad para DD5 e inmunoelectroforesis fue la presencia del arco $5 \%$, en su ausencia. ta deteccion de 20 más bandas 0 arcos de precipitación, con identidad perfecta con cualquiec banda del suero control. La presencia de sólo una banda que no correspondiese al arco 5 fur considerada resultado sospechoso de infección hidatídica.

\section{Resultados}

De los 115 casos confirmados quirúrgicamente, en $78(67,8 \%)$ la serología fue positiva a la DD5 y a la inmunoelectroforesis. En 16 $(13,9 \%)$ casos fue sospechosa, por presentar sólo una banda de precipitación que no correspondía al arco 5; los sueros que presentaron una banda fueron incorporados dentro del grupo de negativos (sospechosos), sin embargo en todos (n:16) se confirmó, posteriormente, infección hidatídica, correspondiendo 13 a quistes intactos y 3 a quistes infectados. En 21 sueros $(18,3 \%)$ las reacciones resultaron negativas con ambas técnicas. La localización clínica más frecuente fue pulmonar, seguida de hepática, hepatopulmonar, peritoneal y otras mucho más raras. La mayor proporción de resultados positivos serológicos se detectó en hidatidosis hepática y la hepatopulmonar seguidas de la peritoneal y la pulmonar. En otras 5 localizaciones poco frecuentes ( 2 oseas, una esplénica, una parotídea y una renal), hubo 3 sospechosos y 2 negativos (tabla 1).

La proporción de positividad en relación al estado biológico de los quistes fue más alta en los recientemente rotos $(97,6 \%)$ y menor en los intactos $(40,0 \%)$. Se detectó arco 5 en 39 de los pacientes confirmados $(33,9 \%)$, treinta y cinco con quistes recientemente rotos y cuatro con quistes infectados (tabla 2).

El número de bandas o arcos de precipjtación visualizados en las láminas teñidas fue de tres o mayor en $36,5 \%$ de los sueros, en $30,4 \%$ había dos bandas $y$ en $14,8 \%$ sólo una; se encontró banda 5 única en el suero de un niño con hidatidosis hepática infectada (tabla 3). En el grupo control, compuesto por 70 sueros de nifnos con otras parasitosis, sólo se detectó una banda débil en la DD5 y negativa en la inmunoelectroforesis en una niña con tricocefalosis.

\section{Comentario}

La mayor frecuencia de la localización pulmonar en población infantil ha sido también constatada en publicaciones internacionales ${ }^{8} y$ es diferente de lo observado en adultos en nuestro país, donde prevalece la hepática. La sensi-

\section{Tabla 1}

Hidatidosis infantil. Rendimiento de las técnicas DD5 e IEF en 115 casos según localización

\begin{tabular}{|c|c|c|c|c|c|c|}
\hline \multirow{3}{*}{ Localizaclón } & \multirow{2}{*}{\multicolumn{2}{|c|}{ Casos }} & \multicolumn{4}{|c|}{ DD5 - IEF } \\
\hline & & & \multicolumn{2}{|c|}{ Positividad } & \multicolumn{2}{|c|}{ Sospechesa } \\
\hline & $\mathbf{n}$ & $\%$ & $\mathbf{n}$ & $\%$ & $\mathbf{n}$ & $\%$ \\
\hline Hepática & 42 & 36.5 & 37 & 88,1 & 2 & 4,8 \\
\hline Pulmonar & 47 & 40.9 & 25 & 53,2 & 10 & 21,3 \\
\hline Hepatopulmonar & 12 & 10.4 & 10 & 83.3 & 1 & 8,3 \\
\hline Peritoneal & 9 & 7.8 & 6 & 66.7 & 0 & 0.0 \\
\hline Otras & & & & & & \\
\hline Jocalizaciones & 5 & 4,4 & 0 & 00,0 & 3 & 60,0 \\
\hline Total & 115 & 100.0 & 78 & 67,8 & 16 & 14,1 \\
\hline
\end{tabular}

Tabla 2

Resultados de la DD5 e IEF según el estado biologico de los quistes y su relación con la presencia o ausencia de arco 5

\begin{tabular}{|c|c|c|c|c|c|c|c|}
\hline \multirow{3}{*}{ Clasificación } & \multicolumn{5}{|c|}{ DD5 - IEF } & \multirow{2}{*}{\multicolumn{2}{|c|}{ Sin arco 5}} \\
\hline & \multirow{2}{*}{$\begin{array}{c}\text { Casos } \\
\text { n }\end{array}$} & \multicolumn{2}{|c|}{ Positiva } & \multicolumn{2}{|c|}{ Con arco 5} & & \\
\hline & & $\mathbf{n}$ & $\%$ & $\mathbf{n}$ & $\%$ & $\mathbf{n}$ & $\%$ \\
\hline Recientemente & & & & & & & \\
\hline rotos & 42 & 41 & 97,6 & 35 & 85,4 & 6 & 14,6 \\
\hline Infectados & 33 & 21 & 63,6 & 4 & 19,0 & 17 & 80,9 \\
\hline Intacios & 40 & 16 & 40,0 & 0 & 0,0 & 16 & 100,0 \\
\hline Total & 115 & 78 & 67,8 & 39 & 50,0 & 39 & 50,0 \\
\hline
\end{tabular}


Tabla 3

Hidatidosis infantil. Distribución de los pacientes según el número de bandas de precipitación observadas en DDS e IEF

\begin{tabular}{ccc}
\hline \multicolumn{2}{c}{ Pacientes } & DDs - IEF \\
$\mathbf{n}$ & $\%$ & 0 \\
21 & 18,3 & 1 \\
$17^{*}$ & 14,8 & 2 \\
35 & 30,4 & 3 \\
25 & 21,7 & 4 \\
15 & 13.1 & $5 \mathrm{ymas}$ \\
2 & $\mathbf{1 , 7}$ & Total \\
\hline 115 & 100.0 & \\
\hline
\end{tabular}

* Sólo en un caso informado positivo se observó el arco 5 como banda única, tanto en DD5 en IEF.

bilidad, expresada en mayor reactividad serológica en casos de quistes hepáticos, así como con el estado físico de las membranas (mayor en quistes rotos), es coincidente con otras experiencias $9,10$.

El arco 5 no fue observado en sueros de niños con quistes intactos (hialinos), posiblemente porque el componente antigénico, responsable de dicho arco, no filtre por las membranas intactas o, si lo hace, es en tan mínima concentración que no se logra detectarlo con estas técnicas.

De acuerdo con las normas del Centro Panamericano de Zoonosis, un buen antígeno debe presentar no menos de 7 arcos de precipitación, incluyendo el arco 5 y el B por inmunoelectroforesis para ser utilizado en inmunodiagnóstico de hidatidosis ${ }^{3.4}$. En los sueros estudiados se observaron entre l y 6 bandas y en los sueros controles entre 1 y 10 , por lo tanto se estima que la visualización de una banda o arco, aunque no sea arco 5, correspondería a algún anticuerpo dirigido contra otro determinante antigénico contenido en el líquido hidatídico. Sin embargo, una banda debe ser considerada como resultado sospechoso de infección hidatídica, por la existencia de comunidades antigénicas con otros helmintos, hecho ya demostrado en adultos con hidatidosis complicada, ya que existe reaccion cruzada con antígeno de Cisticercus celullosae" ${ }^{\prime \prime}$ lo que no se observó en sueros de niños. En esta casuística no se detectaron falsos positivos con dos o más bandas, lo que fundamenta al criterio de positividad aplicado en este estudio. Consideramos que los resultados deberían ser informados en términos de ausencia o presencia de anticuerpos antihidatídicos con 0 sin arco 5 , indicándose el número de bandas encontradas en DD5 o inmunoelectroforesis, ya que esta información serviría al clínico para una evaluación más ponderada de la relación huésped-parásito.

Otros autores han obtenido una sensibilidad inferior empleando el criterio de positividad de tres o más bandas ${ }^{9-12}$, pero no se ha descrito en cuántos sueros de pacientes con hidatidosis confirmada se observaron una o dos bandas o arcos de precipitación. Con respecto a la sensibilidad $(67,8 \%)$ y especificidad ( $100 \%)$ observadas en este estudio, el valor predictivo positivo resultante fue $100 \%$ y el valor predictivo negativo $92,5 \%$. Puesto que existen quistes serológicamente silentes, que suelen sospecharse por técnicas de imágenes, confirmados por cirugía ${ }^{13}$, los resultados negativos no descartan totalmente la presencia de hidatidosis. Además, al comparar la sensibilidad de las diferentes técnicas serológicas, las de inmunoprecipitación son capaces de detectar solamente entre 10 y $60 \mu \mathrm{g} / \mathrm{ml}$ de anticuerpos circulantes, en cambio ELISA delecta entre 0,01 y $0,001 \mu \mathrm{g} / \mathrm{ml}$, lo que determina una sensibilidad significativamente mayor de esta última. Recomendamos estas pruebas en el diagnóstico de la hidatidosis en pediatría, por su especificidad, bajo costo y factibilidad en cualquier laboratorio asistencial, enfatizando el empleo de antígenos estandarizados, asociadas a otras pruebas como ELISA o HAI para complementar el diagnóstico clínico ${ }^{14}$.

\section{Resumen}

Entre 1982 y 1991 se aplicaron las técnicas DD5 e inmunoelectroforesis en 500 sueros de niños sintomáticos con sospecha de enfermedad hidatídica y 70 con otras parasitosis confirmadas. En 115 se comprobó quirúrgicamente uno o más quistes hidatídicos. La DD5 e inmunoelectroforesis resultaron positivas en 78 casos $(67,8 \%)$ y sospechosas en $16(13,9 \%)$. La localización hepática presentó la mayor sensibilidad $(88.1 \%)$. El arco 5 se identificó en el $33,9 \%$ de los sueros confirmados $y$, de éstos, en 35 de 42 quistes rotos. Se consideró como criterio de positividad la presencia del arco 5 o, en su ausen- 
cia, la detección de dos o más bandas de precipitacion, fundamentando este criterio en el hecho que en 35 de los 115 casos confirmados quirúrgicamente $(30,4 \%)$ identificamos dos bandas en la DD5 e inmunoelectroforesis y no detectamos falsos positivos con más de una banda.

(Palabras clave: hidatidosis, diagnóstico serológico, arco S, inmunoelectroforesis.)

\section{Referencias}

1. Serra I. Reyes $\boldsymbol{H}$ : Hidatidosis humana en cuatro países de Sudamérica. Bol of Sanit Panam 1989; 106 : $527-530$.

2. Schenone $H$, Rojas A, Villarroel F, Schenone $H$. (hijo): Algunos aspectos de la epidemiologia de la hidatidosis humana y animal en Chile, con especial referencia al decenio 1975-1984. Bol Chil Parasit 1987; 42: 49-58.

3. Varela-Díaz $V$, Coltorri $E$ : Técnicas para el diagnóstico inmunológico de la hidatidosis humana. OPS/OMS. Centro Panamericano de Zoonosis, 1974.

4. Colrorti $E$, Varela $D$. Detection of antibodies against Echinococcus granulosus arc 5 antigens by double diffusion test. Trass R Soc Trop Med Hyg 1987; 72: 226-229.

5. Pezzella $M$, Galli $C$, Vullo $V$, Zennaro $F$, Detia $S$, Sorice F: Echinococcus granulosus antigens: comparative analysis of human, bovine and ovine hydatid fJuids. Ann Trop Med Parasitol 1984; 78 ; $549-551$.

6. Coltorti $E$ : Standarization and evaluation of an enzyme immunoassay. A screening test for the seroepide- miology of human hydatidosis. Am J Trop Med Hyg 1986; 35: 100-105.

7. Rickard M, Honey $R$, Brumley J, Mitchell G: Serological diagnosis and pos-operative surveillance of human hydatid disease. II The enzyme-linked immunosorbent assay (ELISA) using various antigens. Pathology 1984: 16: 211-215.

8. Berchi J, Cano d, Diaz J. Cuadrados A, Gomez F: Hidatidosis en la infancia: Nuestros planteamientos actuales. XПI Congreso Intemacional de Hidatidología. Libro de Ponencias. Madrid-Espafia, del 24 al 27 de abril 1985; 222-226.

9. Mercado $R$, Atías A, Astorga B, Lorca B: Reacción de doble difusión en agar con detección del arco 5 en el diagnóstico de la hidatidosis. Bol Of Sanit Panam 1988; 105: 159-163.

10. Yarzabal L, Retamal $C$, Sepúlveda $R$, Guachalla $J$, Kieguel $C$ : Aplicacion de la inmunoelectroforesis al diagnóstico de la hidatidosis pulmonar en Chile. Rev Inst Med Trop. Săo Paulo 1975; 17: 263-268.

11. Shepherd J, Mc Manus D: Specific and cross-reactive antigens of Echinococcus granulosus hydatid cyst fluid. Mol Biochem Parasitol 1987; 25; 143.154.

12. Lorca M, Denegri M, Garcfa A. Siłva B: Inmunodiagnóstico de hidatidosis humana. Parasitol al Dia 1993; 17: 25-29.

13. Varela-Diaz V, Guarnera E, Coltori E: Ventajas y limitaciones de los métodos innunólogiços y de detección por imágenes para el diagnóstico de la hidatidosis. Bol Of Sanit Panam 1986; 100: 369-383.

14. Bonifacio R: Departamento de Parasitología, Facultad de Medicina, Montevideo, Uruguay: Seroprevalence of Echinococcus granulosus infection in a Uruguay rural human population. Trens R Soc Trop Med Hyg Tropical 1991; 85: 769-772. 